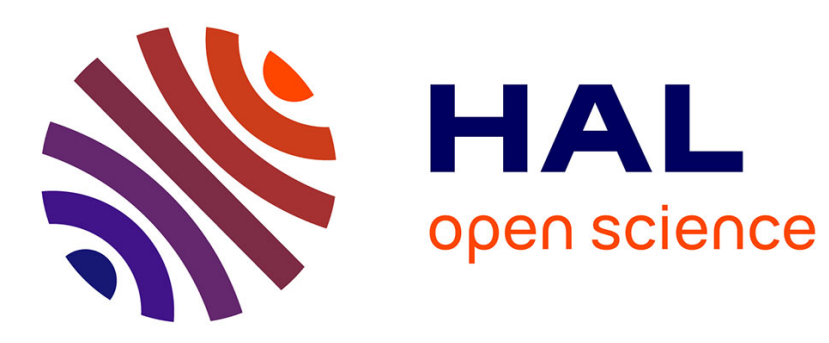

\title{
Microsporidiosis after liver transplantation: A French nationwide retrospective study
}

Jérôme Dumortier, Sylvie Radenne, Nassim Kamar, Filomena Conti, Armand Abergel, Audrey Coilly, Claire Francoz, Pauline Houssel-Debry, Claire Vanlemmens, Noemie Laverdure, et al.

\section{To cite this version:}

Jérôme Dumortier, Sylvie Radenne, Nassim Kamar, Filomena Conti, Armand Abergel, et al.. Microsporidiosis after liver transplantation: A French nationwide retrospective study. Transplant Infectious Disease, 2021, pp.e13665. 10.1111/tid.13665 . hal-03280899

\section{HAL Id: hal-03280899 https://hal.science/hal-03280899}

Submitted on 9 Jul 2021

HAL is a multi-disciplinary open access archive for the deposit and dissemination of scientific research documents, whether they are published or not. The documents may come from teaching and research institutions in France or abroad, or from public or private research centers.
L'archive ouverte pluridisciplinaire $\mathbf{H A L}$, est destinée au dépôt et à la diffusion de documents scientifiques de niveau recherche, publiés ou non, émanant des établissements d'enseignement et de recherche français ou étrangers, des laboratoires publics ou privés. 
DR JEROME DUMORTIER (Orcid ID : 0000-0002-7824-5396)

PROFESSOR NASSIM KAMAR (Orcid ID : 0000-0003-1930-8964)

PROFESSOR ARMAND ABERGEL (Orcid ID : 0000-0001-7480-1052)

DR AUDREY COILLY (Orcid ID : 0000-0003-3149-8617)

DR PAULINE HOUSSEL (Orcid ID : 0000-0001-9271-9810)

DR NOÉMIE LAVERDURE (Orcid ID : 0000-0002-3217-4035)

DR XAVIER IRIART (Orcid ID : 0000-0002-0998-8962)

DR MARC THELLIER (Orcid ID : 0000-0003-4867-2423)

PROFESSOR ADELA ANGOULVANT (Orcid ID : 0000-0001-7035-8946)

DR NICOLAS ARGY (Orcid ID : 0000-0002-0458-2664)

DR BRICE AUTIER (Orcid ID : 0000-0001-6945-4359)

DR ANNE-PAULINE BELLANGER (Orcid ID : 0000-0003-4144-476X)

PROFESSOR FRANCOISE BOTTEREL (Orcid ID : 0000-0002-3028-2665)

DR CYRIL GARROUSTE (Orcid ID : 0000-0001-5166-5617)

DR PHILIPPE POIRIER (Orcid ID : 0000-0001-9173-2634)

Article type : Original Article

\section{Microsporidiosis after liver transplantation: a French nationwide retrospective study}

Jérôme Dumortier ${ }^{1}$, Sylvie Radenne ${ }^{2}$, Nassim Kamar ${ }^{3}$, Filomena Conti ${ }^{4}$, Armand Abergel ${ }^{5}$, Audrey Coilly ${ }^{6}$, Claire Francoz ${ }^{7}$, Pauline Houssel-Debry ${ }^{8}$, Claire Vanlemmens ${ }^{9}$,

This article has been accepted for publication and undergone full peer review but has not been through the copyediting, typesetting, pagination and proofreading process, which may lead to differences between this version and the Version of Record. Please cite this article as doi: 
Noémie Laverdure ${ }^{10}$, Christophe Duvoux ${ }^{11}$, Xavier $\operatorname{Iriart}^{12}$, Marc Thellier ${ }^{13}$, Adela Angoulvant ${ }^{14}$, Nicolas Argy ${ }^{15}$, Brice Autier ${ }^{16}$, Anne-Pauline Bellanger ${ }^{17}$, Françoise Botterel ${ }^{14}$, Cyril Garrouste ${ }^{18}$, Meja Rabodonirina ${ }^{19}$ \& Philippe Poirier ${ }^{20}$ - for the Groupe de Recherche Français en Greffe de Foie $\left(\mathrm{GReF}^{2}\right)$ and The French Microsporidiosis Network.

${ }^{1}$ Hospices civils de Lyon, Hôpital Edouard Herriot, Unité de transplantation hépatique, et Université Claude Bernard Lyon 1, Lyon,

${ }^{2}$ Hospices civils de Lyon, Hôpital de la Croix-Rousse, Service d'Hépato-Gastroentérologie, Lyon,

${ }^{3}$ CHU Toulouse Rangueil, Département de Néphrologie et Transplantation d'Organes, INSERM U1043, IFR -BMT, Université Paul Sabatier, Toulouse,

${ }^{4}$ APHP - Hôpital de la Pitié Salpêtrière, Service d’hépatologie et transplantation hépatique, Paris,

${ }^{5}$ CHU Clermont-Ferrand, Médecine digestive, Institut Pascal., UMR 6602 UCA CNRS SIGMA, Clermont-Ferrand,

${ }^{6}$ AP-HP, Hôpital Paul Brousse, Centre Hépato-Biliaire, et INSERM, Unité 1193, Villejuif,

${ }^{7}$ APHP, Hôpital Beaujon, Service d'Hépatologie et Transplantation Hépatique - Université Paris Diderot - INSERM U1149, Clichy,

${ }^{8}$ CHU de Rennes, Hôpital de Pontchaillou, Service des Maladies du foie, Rennes,

${ }^{9}$ CHU de Besançon, Hôpital Jean Minjoz, Service d'Hépatologie et Soins Intensifs Digestifs, Besançon,

${ }^{10}$ Hospices civils de Lyon, Hôpital Femme-Mère-Enfant, Service d'Hépato-Gastroentérologie et Nutrition pédiatriques, Bron,

${ }^{11}$ APHP-Hôpital Henri Mondor, Service d'Hépatologie, Créteil,

${ }^{12}$ CHU Toulouse, Hôpital Purpan, Service de Parasitologie-Mycologie, et; Institut Toulousain des Maladies Infectieuses et Inflammatoires (Infinity), Université Toulouse, CNRS UMR5051, INSERM UMR1291, UPS, Toulouse,

${ }_{13}$ APHP - Hôpital de la Pitié Salpêtrière, Service de Parasitologie-Mycologie, Paris,

${ }^{14}$ APHP-Hôpital Bicêtre, Service de Maladies infectieuses et Tropicale, Le Kremlin-Bicêtre,

15 APHP, Hôpital Bichat-Claude Bernard, Service de Parasitologie-Mycologie, Paris,

16 Univ Rennes, CHU Rennes, Inserm, EHESP, Irset (Institut de Recherche en Santé Environnement Travail), UMR_S 1085, Rennes,

${ }_{17}$ CHU de Besançon, Service de Parasitologie-Mycologie, Besançon,

${ }^{18}$ CHU Clermont-Ferrand, Service de Néphrologie et transplantation rénale, Clermont-Ferrand, 
${ }^{19}$ Hospices civils de Lyon, Hôpital de la Croix-Rousse, Service de Parasitologie, et Université Claude Bernard Lyon 1, Lyon,

20 CHU Clermont-Ferrand, Service de Parasitologie-Mycologie, 3iHP, INSERM, Université Clermont Auvergne, Clermont-Ferrand,

France

Address for correspondence:

Jérôme Dumortier, $\mathrm{MD}, \mathrm{PhD}$, pavillon L, Hôpital Edouard Herriot, 69437 Lyon Cedex 03, France fax number: (33) 472110147 phone number: (33) 472110111 E-mail: jerome.dumortier@chu-lyon.fr

Keywords: liver transplantation; microsporidiosis.

Word count $=1775$ words

Abbreviations:

AIDS: acquired immunodeficiency syndrome

LT: liver transplantation

PCR: polymerase chain reaction

SOT: solid organ transplant

Conflict of interest statement: no conflict of interest to declare.

Financial support statement: no financial support.

Authors contributions:

Jérôme Dumortier had the idea of the project and participated in analysis and interpretation of data.

Jérôme Dumortier, Meja Rabodonirina and Philippe Poirier participated in writing of the manuscript. 
Jérôme Dumortier, Sylvie Radenne, Nassim Kamar, Filomena Conti, Armand Abergel, Audrey Coilly, Claire Francoz, Pauline Houssel-Debry, Claire Vanlemmens Noémie Laverdure, Christophe Duvoux, Xavier Iriart, Marc Thellier, Adela Angoulvant, Nicolas Argy, Brice Autier, Anne-Pauline Bellanger, Françoise Botterel and Cyril Garrouste collected the data and approved the final version of the manuscript. 


\section{Abstract}

Background: Microsporidiosis has been largely reported in patients with acquired immunodeficiency syndrome, but emerged as a cause of persistent diarrhea in solid organ transplant patients.

Methods: Through the French Microsporidiosis Network and the Groupe français de recherche en greffe de foie, we collected all microsporidiosis cases identified in liver transplant patients between 1995 and 2020 in France.

Results: We identified 24 liver transplant recipients with microsporidiosis. Sex ratio was balanced and median age was 58.8 (3.5-83.5) years (there were 4 children). Microsporidiosis occurred at a median time of 3.9 (0.1-18.9) years post-transplant. Median duration of diarrhea before diagnosis was 22 days (12-45). Therapeutic care included immunosuppressive therapy changes in 20 patients, as follows: stop cyclosporine or tacrolimus $(n=2)$, dose reduction of cyclosporine or tacrolimus $(\mathrm{n}=12)$, stop MMF $(\mathrm{n}=5)$, dose reduction of corticosteroids $(\mathrm{n}=1)$. In addition, 15 patients received specific therapy against microsporidiosis: fumagilline $(n=11)$ or albendazole $(n=4)$. Median duration of treatment was 14 days (8-45 days). Finally, 7 patients had IS treatment tapering only. Microsporidiosis was complicated by renal failure in 15 patients, requiring dialysis in 1 case. Two patients had infection relapse. No patient presented proven rejection within the 3 months after microsporidiosis. None of the patients died within the 3 months after microsporidiosis.

Conclusions: Microsporidiosis is a very rare infection after liver transplantation but can induce severe deshydratation and renal failure. Therefore, it must be systematically sought in any case of persistent diarrhea after first line screening of frequent infectious causes. 


\section{Introduction}

Microsporidia are spore-forming eukaryotic and opportunistic intracellular pathogens related to fungi ${ }^{1,2}$, which are known to infect both invertebrates and vertebrates hosts. In most human cases, microsporidia are orally transmitted by waterborne or foodborne spores from excreta, and by interindividual contacts; presentation as small epidemic is possible ${ }^{3-6}$. Of the species infecting humans, Enterocytozoon bieneusi is the most frequent and, to a lesser degree, Encephalitozoon intestinalis, Encephalitozoon hellem and Encephalitozoon cuniculi 1, 7, 8. Since the late 1980's, microsporidia have been mostly known as a cause of chronic and wasting diarrhea in patients with acquired immunodeficiency syndrome (AIDS) ${ }^{9}$. Since the late 1990's, a limited number of cases of microsporidiosis have been reported in solid organ transplant (SOT) and bone marrow transplant (BMT) recipients, including less than 20 cases after liver transplantation (LT) ${ }^{7}, 10-13$. Some rare cases of donor-transmitted infections have been reported ${ }^{14,15}$. Related to the two most prevalent species, E. bieneusi and E. intestinalis, diarrhea is the most common presenting symptom, but other clinical manifestations include ocular, renal, pulmonary, cardiac, liver, and central nervous system involvement during microsporidia infection, especially in AIDS patients with low lymphocyte counts ${ }^{2,7}$. E. bieneusi and E. intestinalis can disseminate to the hepatobiliary system leading to cholangitis. During the past decades, diagnostic methods evolved so that detection and identification of microsporidia species can now be made by specific polymerase chain reaction (PCR), in addition to microscopic detection methods ${ }^{2}$. This has probably led to better recognition of cases in recent years.

In France, a microsporidia national network has been set up in 2018 to provide data on the epidemiology of human microsporidiosis. The aim of the present retrospective study was to collect information on history, treatment, and outcome of microsporidiosis in LT recipients in France. 


\section{Patients and methods}

\section{Study population}

The French Microsporidiosis Network was set up in 2018, in order to provide public health authorities with data on the incidence and epidemiology of human microsporidiosis in France. Through the French Microsporidiosis Network and by contact with the French Groupe de recherche français en greffe de foie $\left(\mathrm{GReF}^{2}\right)$, we retrospectively collected all microsporidiosis cases identified in LT recipients between 1995 and 2020. Cases were defined by the presence of persistent diarrhea (ie, $\geq 3$ liquid stools per day for more than 2 weeks) and detection of microsporidia spores by a microscopic examination of fecal smears after Van Gool and/or Weber and/or immunofluorescent staining and/or molecular methods. Identification to the species level was achieved by using species specific antibodies or PCR 7 .

We retrospectively collected clinical information regarding the patient, the transplant, induction and maintenance immunosuppressive regimens, clinical presentation, environmental characteristics, treatment, and outcome.

According to French law (Loi Jardé), anonymous retrospective studies do not require Institutional Review Board approval.

\section{Statistical Analysis}

Continuous variables are described as means ( \pm standard deviation) and/or medians (range) and categorical variables are presented as numbers and frequencies (percentages). 


\section{Results}

\section{Study population}

Twenty-four LT recipients who developed microsporidiosis between 1995 and 2020 in France were identified, from 10 transplant centers. The patient characteristics are reported in Table 1.

Sex ratio was balanced and median age was 58.8 (3.5-83.5) years at the time of microsporidiosis diagnosis. Four patients were younger than 18 years. Three patients received combined kidney and liver transplant. None of the patients had additional immunodepression favoring microsporidiosis such as congenital immune deficiency or HIV infection. Three patients received steroids boluses for the treatment of acute rejection in the 3 months prior to diagnosis of microsporidiosis. We found epidemiological information that could be associated with the occurrence of microsporidiosis in 6 patients, including 3 cases during a local epidemic (waterborne outbreak in an artificial lake ${ }^{6}$ ), 2 cases in 2 children sisters ${ }^{12}$ and 1 case traveled recently in low sanitary area.

\section{Clinical Characteristics}

Microsporidiosis occurred at a median time of 3.9 years (0.1-18.9) post-transplant. It occurred within 6 months post-transplant in 4 cases. Median duration of diarrhea before diagnosis was 22 days (14-45). Diagnosis was made from stool analysis in all cases, by direct methods in 9 cases or PCR in the 15 others. None of the patients had coinfection. None of the patients had recognized associated extraintestinal location. Hospitalisation was required in all cases except one. In one case, the patient was admitted in Intensive Care Unit, due to the need of transient dialysis (the patient was not a combined liver/kidney recipient). Median hospital stay was 15 days (4-36). Weight loss (79.2\%) and dehydration-related acute kidney failure (62.5\%) were frequent.

\section{Treatment and Outcome}

After diagnosis of microsporidiosis, immunosuppressive therapy was modified in 20 patients, as follows: stop cyclosporine or tacrolimus $(n=2)$, dose reduction of cyclosporine or tacrolimus $(\mathrm{n}=12)$, stop MMF $(\mathrm{n}=5)$, dose reduction of corticosteroids $(\mathrm{n}=1)$. In addition, 15 patients received specific therapy against microsporidiosis: fumagilline $(n=11)$, or albendazole $(n=4)$. Median duration of treatment was 14 days (8-45 days). Finally, 7 patients had IS treatment tapering only. Outcome was favorable in all cases, but 2 patients relapsed (1 patient had 2 relapse episodes). No systematic stool screening was done after treatment. Relapse cases were identified because of recurrent symptoms.

No patient presented proven rejection within the 3 months after microsporidiosis. None of the patients died within the 3 months after microsporidiosis. 


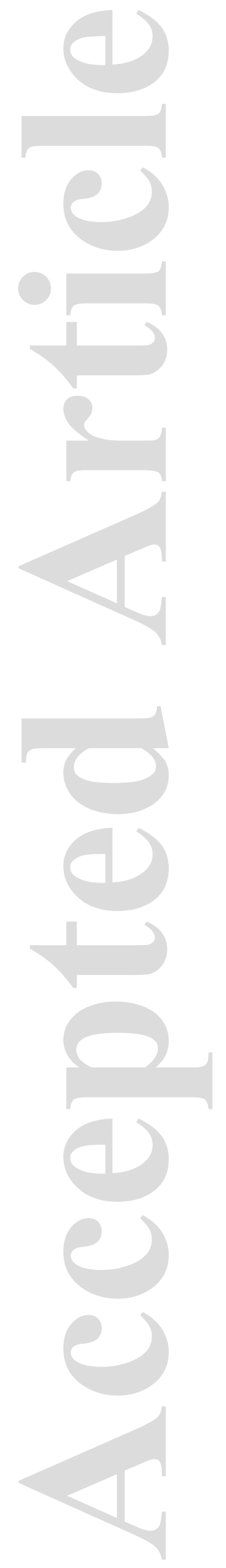




\section{Discussion}

Although recently attached to the Fungi group, microsporidia are ubiquitous unicellular microorganisms with an obligate intracellular stage, like some parasites (these microorganisms were classified as protozoa for a long time). Most cases of microsporidiosis were first described during the AIDS pandemic, highlighting its opportunistic skills ${ }^{1}$. During the $21^{\text {st }}$ century, incidence has currently decreased in this population. Nowadays, SOT recipients are considered as a risk group for microsporidiosis; nevertheless, no more than 100 cases have been reported in SOT by now, mainly in renal transplant recipients ${ }^{12,13}$. We therefore report herein the largest cohort of cases in LT recipients, based on a retrospective nationwide study. We believe that this series is probably not entirely exhaustive, except in the very recent period, after the creation of the French Microsporidiosis Network in 2018. In summary, we identified approximately one case per year in France during the last 25 years. Nevertheless, it cannot be excluded that mild cases of microsporidiosis, diagnosed or not, which did not lead to hospitalization, may have not been captured by the present survey.

Diagnosis of microsporidiosis has been established between 1 month and 28 years after LT, and this confirms that infection can occur at any time after a transplantation, even in the very long term. As in our patients, E. bieneusi has been involved in the majority (almost all) of reported cases. The existence of microsporidia asymptomatic carriers has been supported, especially in the immunocompromised host ${ }^{16}$. Asymptomatic carriers could therefore disseminate the infection. Gastrointestinal microsporidiosis can be diagnosed using stool microscopy of at least three stool samples with chromotrope and chemofluorescent stains or immunofluorescence ${ }^{2,}{ }^{17}$. More recently, in house and commercialized PCR assays for detection and identification to the species level exhibit excellent diagnostic performance, and some of them allow simultaneous detection of Cryptosporidium $\mathrm{sp}^{2,18-20}$.

Infection with E. bieneusi is usually restricted to the intestinal tract, and is a major cause of acute or persistent diarrhea. Clinical manifestations also include weight loss, nausea, and abdominal pain ${ }^{2}$. No case of disseminated microsporidiosis or biliary involvement was reported in our cohort. Nevertheless, severe profuse diarrhea can be complicated by renal failure as illustrated in many of our cases. Gastrointestinal disorders, and especially diarrhea, in SOT recipients may have various origins including immunosuppressive drugs and infections. Microsporidiosis is undoubtedly a rare cause of diarrhea, but not exceptional. In the prospective study by Moniot and coll., among 82 French kidney transplants presenting with diarrhea, microsporidiosis and 
cryptosporidiosis accounted for $2.4 \%$ and $7.3 \%$, respectively ${ }^{19}$. However, prevalences were probably underestimated as this work did not distinguish between infectious and non-infectious diarrhea. Deltombe and coll. prospectively assessed the infectious causes of diarrhea in adult kidney and/or pancreas transplant recipients patients, with a specific focus on cryptosporidiosis and microsporidiosis, in France ${ }^{21}$. During a 12 months period, all patients who presented with diarrhea had an exhaustive stool sample analysis. Out of 73 enrolled patients, 36 had infectious diarrhea (49.3\%), including 2 cases of co-infection, 1 to 321 months after transplantation. Viruses ranked first (17/36), followed by parasites and fungi (11/36) and bacteria (5/36). Cryptosporidiosis was the most common parasitic/fungal disease $(n=6,16.7 \%)$ but there were 4 cases of microsporidiosis (11.1\%). The estimated prevalence of cryptosporidiosis and microsporidiosis in the global cohort of 1624 recipients was 0.37 and $0.24 \%$, respectively.

Therapeutic options in microsporidial infections are limited. Efficacy strongly depends on the causal species. The best criteria of therapeutic success should be the resolution of the clinical manifestations and negative samples (absence of spores), which is not always available in all cases. At the present time, albendazole and fumagillin are the most effective compounds against $E$. intestinalis and E. bieneusi, respectively. The use of these two drugs depended in our cohort on identification of species and/or availability (fumagillin was not available at the time of oldest cases). In SOT recipients, reduction of immunosuppression is part of the treatment, as much as possible, that was the case in the vast majority of our patients. A very recent study evaluated the efficacy and safety of fumagillin in a real-life setting in France, as required by the French Medicine Agency ${ }^{22}$. All patients receiving fumagillin between 2007 and 2018 were enrolled in a prospective study to evaluate its efficacy and safety. There were 166 patients (including 6 children) and $84 \%$ were transplant recipients. Serious adverse events were reported in 41 patients $(25 \%)$, mainly thrombocytopenia $(15 \%)$ and neutropenia $(5 \%)$, with two haemorrhagic events leading to one death. Severe thrombocytopenia $(<50 \mathrm{G} / \mathrm{L})$ developed in 50 patients $(29.6 \%)$, neutropenia $(<1 \mathrm{G} / \mathrm{L})$ in 20 patients $(11.8 \%)$ and severe anaemia $(<8 \mathrm{~g} / \mathrm{dL})$ in 21 patients $(12.4 \%)$. Such hematological side-effects are of great clinical relevance in SOT recipients, because these are frequent side-effects of some immunosuppressive drugs. At the end of treatment, $94 \%$ of patients with available stool examination $(n=132)$ had no spores detected; among 99 patients with available follow-up after the end of treatment, three cases of relapse were documented. After initial favorable outcome, infection relapse is probably rare (2 cases in the present series, i.e. $8.3 \%)$. 
In conclusion, when persistent diarrhea occurs in SOT patients, microsporidiosis infection can induce severe dehydration and must be searched systematically using specific conventional and molecular tools. Diagnosis can therefore lead to rapid treatment adapted on causal species. 


\section{Acknowledgements}

The authors thank all French liver transplant centers and all parasitology laboratories for having screened their local data basis.

\section{The French Microsporidiosis Network $=$}

CH Le Havre (LABBE Franck), CHU Amiens (DAMIANI Céline, LE GOVIC Yohann, TOTET Anne), CHU Angers (DE GENTILE Ludovic, LEMOINE Jean-Philippe), CHU Besançon (BELLANGER Anne Pauline), CHU Bordeaux (ACCOCEBERRY Isabelle, DELHAES Laurence, GABRIEL Frédéric, MILLET Pascal), CHU Brest (LE GAL Solène, NEVEZ Gilles), CHU Caen (BONHOMME Julie, CAPITAINE Agathe), CH Cayenne (DEMAR Magalie), CHU Clermont-Ferrand (MONIOT Maxime, NOURRISSON Céline), CHU Créteil (ANGEBAULT Cécile, BOTTEREL Françoise, FOULET Françoise), CHU Dijon (BASMACIYAN Louise, DALLE Frédéric, VALOT Stéphane), CH Fort-de-France (DESBOIS-NOGARD Nicole), CHU Grenoble (ROBERT Gladys), CHU Lille (DELEPLANCQUE Anne-Sophie, FREALLE Emilie, LEROY Jordan), CHU Limoges (AJZENBERG Daniel, DURIEUX Marie-Fleur), CHU Lyon (CHAPEY-PICQ Emmanuelle, DUPONT Damien, MENOTTI Jean, RABODONIRINA Meja), CHU Marseille (LOLLIVIER Coralie), CHU Montpellier (BASTIEN Patrick), CHU Nancy (DEBOURGOGNE Anne, MACHOUART Marie), CHU Nantes (LAVERGNE Rose-Anne, MORIO Florent), CHU Nice (DELAUNAY Pascal, POMARES Christelle, SIMON Loïc), CHU Nîmes (SASSO Milène), CHU Paris Bichat (ARGY Nicolas, HOUZE Sandrine), CHU Paris Cochin (YERA Hélène), CHU Paris HEGP (DANNAOUI Eric), CHU Paris Necker CHU (BOUGNOUX Marie-Elisabeth, SITTERLE Emilie), CHU Paris Pitié-Salpêtrière (KAPEL Nathalie, TANTAOUI Ilhame, THELLIER Marc), CHU Paris Saint Antoine (BELKACEM BELKADI Ghania, MORENO-SABATER Alicia), CHU Paris Saint Louis (HAMANE Samia), CHU Pointe-à-Pitre (NICOLAS Muriel), CHU Poitiers (PERRAUD Estelle), CHU Reims (CHEMLA Cathy, VILLENA Isabelle), CHU Rennes (AUTIER Brice), CHU Rouen (COSTA Damien, FAVENNEC Loïc), CHU Saint Etienne (FLORI Pierre), CHU Strasbourg (BRUNET Julie), CHU Toulouse (BERRY Antoine, IRIART Xavier), CHU Tours (CHESNAY Adélaïde, DESOUBEAUX Guillaume), Lab. Bioceane (ARTUR Fabienne), Lab. CERBA (VERDURME Laura), Lab. Cerballiance Finistère (FOULQUIER Jean-Baptiste, PRIGENT Gwenole), Lab. GLBM (CHATELAIN Rémi), Lab. LABEXA (LESTHELLE Sophie) 


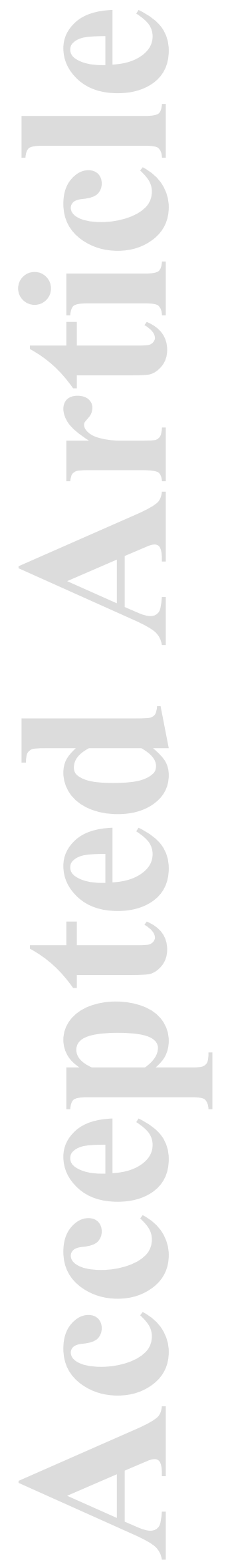




\section{References}

1. Didier ES and Weiss LM. Microsporidiosis: current status. Curr Opin Infect Dis 2006; 19(5): 485492.

2. Anane S and Attouchi H. Microsporidiosis: epidemiology, clinical data and therapy. Gastroenterol Clin Biol 2010; 34(8-9): 450-464.

3. Mathis A, Weber R, and Deplazes P. Zoonotic potential of the microsporidia. Clin Microbiol Rev 2005; 18(3): 423-445.

4. Ramanan P and Pritt BS. Extraintestinal microsporidiosis. J Clin Microbiol 2014; 52(11): 38393844.

5. Desoubeaux G, Nourrisson C, Moniot M et al. Genotyping Approach for Potential Common Source of Enterocytozoon bieneusi Infection in Hematology Unit. Emerg Infect Dis 2019; 25(9): 1625-1631.

6. Cotte L, Rabodonirina M, Chapuis F et al. Waterborne outbreak of intestinal microsporidiosis in persons with and without human immunodeficiency virus infection. J Infect Dis 1999; 180(6): 2003-2008.

7. Didier ES and Weiss LM. Microsporidiosis: not just in AIDS patients. Curr Opin Infect Dis 2011; 24(5): 490-495.

8. Stentiford GD, Becnel J, Weiss LM et al. Microsporidia - Emergent Pathogens in the Global Food Chain. Trends Parasitol 2016; 32(4): 336-348.

9. Eeftinck Schattenkerk JK, van Gool T, van Ketel RJ et al. Clinical significance of small-intestinal microsporidiosis in HIV-1-infected individuals. Lancet 1991; 337(8746): 895-898.

10. Guerard A, Rabodonirina M, Cotte L et al. Intestinal microsporidiosis occurring in two renal transplant recipients treated with mycophenolate mofetil. Transplantation 1999; 68(5): 699-707.

11. La Hoz RM and Morris MI. Intestinal parasites including Cryptosporidium, Cyclospora, Giardia, and Microsporidia, Entamoeba histolytica, Strongyloides, Schistosomiasis, and Echinococcus: Guidelines from the American Society of Transplantation Infectious Diseases Community of Practice. Clin Transplant 2019; 33(9): e13618.

12. Desoubeaux G, Maakaroun-Vermesse Z, Lier C et al. Successful treatment with fumagillin of the first pediatric case of digestive microsporidiosis in a liver-kidney transplant. Transpl Infect Dis 2013; 15(6): E250-259.

13. Fabiani S, Fortunato S, and Bruschi F. Solid Organ Transplant and Parasitic Diseases: A Review of the Clinical Cases in the Last Two Decades. Pathogens 2018; 7(3).

14. Hocevar SN, Paddock CD, Spak CW et al. Microsporidiosis acquired through solid organ transplantation: a public health investigation. Ann Intern Med 2014; 160(4): 213-220. 
15. Smith RM, Muehlenbachs A, Schaenmann J et al. Three Cases of Neurologic Syndrome Caused by Donor-Derived Microsporidiosis. Emerg Infect Dis 2017; 23(3): 387-395.

16. Kicia M, Wesolowska M, Kopacz Z et al. Prevalence and molecular characteristics of urinary and intestinal microsporidia infections in renal transplant recipients. Clin Microbiol Infect 2016; 22(5): 462 e $465-469$.

17. Field AS and Milner DA, Jr. Intestinal microsporidiosis. Clin Lab Med 2015; 35(2): 445-459.

18. Saigal K, Khurana S, Sharma A, Sehgal R, and Malla N. Comparison of staining techniques and multiplex nested PCR for diagnosis of intestinal microsporidiosis. Diagn Microbiol Infect Dis 2013; 77(3): 248-249.

19. Moniot M, Nourrisson C, Faure C et al. Assessment of a multiplex PCR for the simultaneous diagnosis of intestinal cryptosporidiosis and microsporidiosis: epidemiological report from a French prospective study. J Mol Diagn 2020.

20. Morio F, Poirier P, Le Govic Y et al. Assessment of the first commercial multiplex PCR kit (ParaGENIE Crypto-Micro Real-Time PCR) for the detection of Cryptosporidium spp., Enterocytozoon bieneusi, and Encephalitozoon intestinalis from fecal samples. Diagn Microbiol Infect Dis 2019; 95(1): 34-37.

21. Deltombe C, Lefebvre M, Morio F et al. Cryptosporidiosis and microsporidiosis as causes of diarrhea in kidney and/or pancreas transplant recipients. Med Mal Infect 2020; 50(5): 407-413.

22. Maillard A, Scemla A, Laffy B, Mahloul N, and Molina JM. Safety and efficacy of fumagillin for the treatment of intestinal microsporidiosis. A French prospective cohort study. J Antimicrob Chemother 2020. 
Table 1. Characteristics of the study population $(n=24)$

\section{Baseline characteristics}

Age: median (range), y

$58.8(3.5-83.5)$

Sex ratio (female/male)

Type of organ transplantation

Liver only

Liver/Kidney

First transplant

Adults/Children

Initial liver disease

Alcoholic liver disease

Viral liver disease

other

Initial immunosuppressive regimen (induction)

Anti-CD25

OKT3

Anti-thymocyte globulin

Maintenance immunosuppressive regimen

Corticosteroids

Tacrolimus

Median trough level at time of diagnosis of microsporidiosis (range), $\mathrm{ng} / \mathrm{mL}$

$7.6(5.5-18.9)$

Cyclosporin

Median trough level at time of diagnosis of microsporidiosis (range), $\mathrm{ng} / \mathrm{mL}$

MMF

Sirolimus/everolimus

Organ rejection before microsporidiosis (in last $3 \mathrm{mo}$ )

\section{Clinical and biological presentation of microsporidiosis}

Median duration of microsporidiosis symptoms before diagnosis, $\mathrm{d}$

Median time interval between transplantation and infection (range), y

Symptoms

Diarrhea

Fever

Nausea

Abdominal pain

Blood in stool

Stool's nb/d 
Weight loss

Weight loss (kg)

Acute renal failure (> 20\% decrease of GFR)

Biological characteristics at diagnosis

Median lymphocyte count, $/ \mathrm{mm}^{3}$

$760(200-2700)$

Lymphopenia $<500 / \mathrm{mm}^{3}$

Microsporidia species

Enterocytozoon bieneusi unknown

ATG, antithymoglobulin; MMF, mycophenolate mofetil.

Data are $\mathrm{n}$ unless otherwise indicated. 